Article

\title{
Ku-Band Sea Surface Radar Backscatter at Low Incidence Angles under Extreme Wind Conditions
}

\author{
Xiuzhong Li ${ }^{1,2}$, Biao Zhang ${ }^{1,2, *}$, Alexis Mouche ${ }^{1,3, *}$, Yijun He ${ }^{1,2}$ and William Perrie ${ }^{1,4}$ \\ 1 School of Marine Sciences, Nanjing University of Information Science and Technology, \\ Nanjing 210044, China; lixiuzhong@nuist.edu.cn (X.L.); yjhe@nuist.edu.cn (Y.H.); \\ William.Perrie@dfo-mpo.gc.ca (W.P.) \\ 2 Jiangsu Research Center for Ocean Survey and Technology, Nanjing 210044, China \\ 3 Laboratoire d'Oceanographie Spatiale, Centre de Brest, IFREMER, Plouzané 29280, France \\ 4 Fisheries and Oceans Canada, Bedford Institute of Oceanography, Dartmouth, \\ Nova Scotia, NS B2Y4A2, Canada \\ * Correspondence: zhangbiao@nuist.edu.cn (B.Z.); Alexis.Mouche@ifremer.fr (A.M.); \\ Tel.: +86-25-5869-5692 (B.Z.)
}

Academic Editors: Xiaofeng Yang, Xiaofeng Li, Ferdinando Nunziata, Alexis Mouche and Prasad S. Thenkabail Received: 14 March 2017; Accepted: 9 May 2017; Published: 12 May 2017

\begin{abstract}
This paper reports Ku-band normalized radar cross section (NRCS) at low incidence angles ranging from $0^{\circ}$ to $18^{\circ}$ and in the wind speed range from 6 to $70 \mathrm{~m} / \mathrm{s}$. The precipitation radar onboard the tropical rainfall measuring mission and Jason- 1 and 2 have provided 152 hurricanes observations between 2008 and 2013 that were collocated with stepped-frequency microwave radiometer measurements. It is found that the NRCS decreases with increasing incidence angle. The decrease is more dramatic in the $40-70 \mathrm{~m} / \mathrm{s}$ range of wind speeds than in the $6-20 \mathrm{~m} / \mathrm{s}$ range, indicating that the NRCS is very sensitive to low incidence angles under extreme wind conditions and insensitive to the extreme wind speed. Consequently, the sea surface appears relatively "smooth" to Ku-band electromagnetic microwaves. This phenomenon validates the observed drag coefficient reduction under extreme wind conditions, from a remote sensing viewpoint. Using the NRCS dependence on incidence angle under extreme wind conditions, we also present an empirical linear relationship between NRCS and incidence angles, which may assist future-satellites missions operating at small incidence angles to measure sea surface wind and wave field.
\end{abstract}

Keywords: NRCS; extreme wind conditions; low incidence angles

\section{Introduction}

Tropical cyclones (also called hurricanes or typhoons) are always associated with high wind speeds. The wind speed plays a crucial role in air-sea interactions, numerical forecasting models, and tropical cyclone intensity. Active microwave remote sensors have advantages for estimating wind speeds because the normalized radar cross section (NRCS, $\sigma^{0}$ ) of the sea surface varies with the roughness and whitecaps or the foam effects that are driven by high wind speeds. The NRCS is a critical parameter for ocean remote sensors such as synthetic aperture radar (SAR) devices, scatterometers, and altimeters. Besides wind speeds at the sea surface, the NRCS can be used to detect ship targets at the sea surface [1], ocean surface currents [2], ocean wave spectra [3], and other ocean surface information.

However, most NRCS applications are limited to low or moderate wind conditions. Several researchers have analyzed the C-band NRCS saturation at wind speeds up to $35 \mathrm{~m} / \mathrm{s}$ [4-6]. Donnelly et al. [7] and Carswell et al. [8] studied the Ku- and C-band NRCS up to wind speeds of $45 \mathrm{~m} / \mathrm{s}$. Thus far, only Fernandez et al. [9] have presented the Ku and C-band NRCS up to wind speeds of $65 \mathrm{~m} / \mathrm{s}$. In all of these reports, the co-polarization (VV) NRCS saturated at high wind speeds 
up to $25 \mathrm{~m} / \mathrm{s}$. Non-saturated cross-polarization (HV or VH) NRCS variation at high wind speeds has also been reported [10-14].

NRCS analyses at low incidence angles and low wind conditions have been frequently reported [15-18]. Some researchers consider that the NRCS under high wind conditions can be extrapolated from the NRCS characteristics in moderate wind conditions [19-21]. At high winds (up to $35 \mathrm{~m} / \mathrm{s}$ ), Quilfen et al. [22] empirically derived an inverse relationship between the sea surface roughness and altimeter backscatter. However, at wind speeds exceeding $35 \mathrm{~m} / \mathrm{s}$, the collocated data are too sparse to analyze the $\sigma^{0}$ characteristics with statistical confidence.

The paper collocates the NRCS from the precipitation radar (PR) of the tropical rainfall measuring mission (TRMM) and the Jason- 1 and 2 altimeter observations, and the stepped-frequency microwave radiometer (SFMR) wind speed measurements up to $70 \mathrm{~m} / \mathrm{s}$. Subsequently, we derive a new NRCS dependence on wind speed at small incidence angles. Section 2 introduces the datasets, and Section 3 presents the data acquisition methodology. Then Section 4 gives results of relatively common moderately intense wind conditions and the newly proposed NRCS characteristic. The relationship between NRCS and incidence angle is also presented in this section. Discussion and conclusions are given in Sections 5 and 6, respectively.

\section{Dataset}

To acquire the NRCS at extremely high wind conditions, NRCS data at low incidence angles were collected from the standard products 2A21 (version-7) of PR and the geophysical data record (GDR) of Jason-1 and 2. The wind speeds were obtained from the National Oceanic Atmospheric Administration (NOAA) Hurricane Research Division (HRD) SFMR along-track measurements in hurricanes. The datasets are summarized and analyzed as follows.

\subsection{TRMM PR}

PR is a spaceborne Ku-band horizontal polarization radar onboard TRMM that has measured precipitation since 1997. The PR antenna is an electronically scanned phased array that scans a planar cross-track area through the nadir (in fact, as the satellite travels very quickly, the scanning track is not strictly vertical to the along-track direction). The nadir spatial resolution of the PR is $5.0 \mathrm{~km}$ (cross-track) $\times 4.1 \mathrm{~km}$ (along-track). Since the boost of the satellite orbit in 2001 to higher altitude, the swath width has been extended to $250 \mathrm{~km}$. The 49 incidence angles vary from approximately $-18^{\circ}$ to $18^{\circ}$.

PR is the first instrument designed to measure the reflectivity of rain from space. The technique is that short pulses are transmitted at Ku-band, and the time delay and strength of the echo gives the distance and intensity of the rain. One of the key points with this technique is to determine the rain attenuation effect at a location. In order to solve this problem, one needs to know the strength of the sea surface reflectance, which varies according to the prevailing wind conditions [23]. Liao and Meneghini [24] compared the performances of the version-6 PR product before and after the satellite boost with a ground-based weather surveillance radar (WSR-88D) in Melbourne, FL. The PR product maintained its calibration accuracy of about $1 \mathrm{~dB}$. Although the orbit boost reduced the NRCS by $0.67-0.88 \mathrm{~dB}$, the accuracy of the PR $\sigma^{0}$ remained within $1 \mathrm{~dB}$ [25].

\subsection{Jason-1 and 2}

Jason-1 and Jason-2 were launched in 2001 and 2008, respectively. Jason-1 has expired but Jason-2 remains in orbit. This study uses the $0^{\circ}$ NRCS of Jason- 1 and 2 from the Ku bands, acquired from 2008 to 2012. The temporal and spatial intervals during the matchup were required to be within $60 \mathrm{~min}$ and $100 \mathrm{~km}$, respectively. The product GDR-c of Jason-1 contains 1-Hz measurements, so points with less than 10 valid NRCSs were eliminated. For Jason-2, the "qual_alt_1hz_sig0_ku" (a quality flag variable in the Ku-band NRCS product) of GDRs are flagged as "good" and these values are retained. 
Both GDRs flagged "no rain" are selected. In total, Jason-1 and Jason-2 were able to contribute 1209 and 3046 collocated pairs, respectively.

\subsection{SFMR}

The SFMR onboard NOAA WP-3D aircraft has been the prototype for a new generation of operational airborne remote sensing instruments designed for measuring the surface winds and rainfall in hurricanes since 1984 [26]. The SFMR operates at 4.6-7.2 GHz and measures meteorological parameters such as wind speed and rain rate [27]. The temporal and spatial resolutions of the measured wind speed are $1 \mathrm{~s}$ and $1.5 \mathrm{~km}$, respectively. The wind speeds are estimated at $10 \mathrm{~m}$ above the sea surface by SFMR; they have been validated by the dropwindsonde measurements and the root-mean-square error (RMSE) is approximately $4 \mathrm{~m} / \mathrm{s}$, or $5 \%-25 \%$ [28]. Since 2007, the SFMR onboard the Air Force Reserve Command has measured the wind speed using the model developed by Uhlhorn and Black [28]. The SFMR-derived wind speeds in hurricanes have also been validated against those retrieved by cross-polarized SAR image, with a bias and RMSE of $-0.89 \mathrm{~m} / \mathrm{s}$ and $3.24 \mathrm{~m} / \mathrm{s}$, respectively [10]. Recently, the SFMR measurements of the surface winds in tropical cyclones with heavy precipitation have been further improved using a new relationship between microwave absorption and rain rate [29]. This relationship significantly decreased the surface-wind retrieval bias in the presence of rain at weak hurricane wind speeds.

\section{Methodology}

152 hurricanes observations were collected from the TRMM PR between 2008 and 2013, which were collocated with SFMR measurements. The temporal and spatial intervals for collocations were $30 \mathrm{~min}$ and $50 \mathrm{~km}$, respectively. For each collocated data pair (denoting $1 \mathrm{~s}$ of SFMR data and one incidence angle of PR), the wind speed and rain rate from SFMR and the NRCS from the PR were recorded. The collocated dataset contains $29,798,600$ points, of which $87.22 \%$ and $58.11 \%$ are below $5 \mathrm{~mm} / \mathrm{h}$ and $2 \mathrm{~mm} / \mathrm{h}$, respectively. Only 140,795 points correspond to wind speeds above $40 \mathrm{~m} / \mathrm{s}$. The distribution of the wind speeds between $40 \mathrm{~m} / \mathrm{s}$ and $70 \mathrm{~m} / \mathrm{s}$ is shown in Figure 1 . The numbers in each of the wind speed bin do not have large discrepancies among one another.

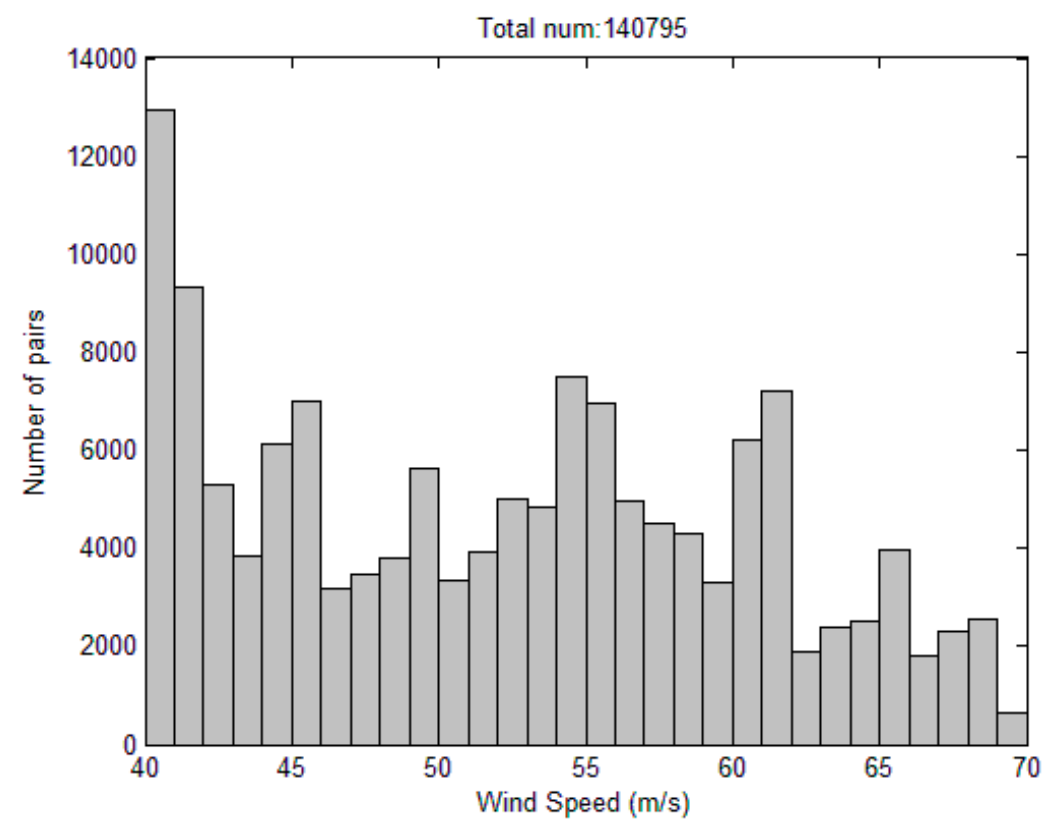

Figure 1. Wind speed histogram of collocated data pairs $(140,795)$ between precipitation radar (PR)-observed normalized radar cross section (NRCS) and stepped-frequency microwave radiometer (SFMR)-measured wind speed ranging from 40 to $70 \mathrm{~m} / \mathrm{s}$. 
Typically, strong winds in intense storms bring intense rainfall. To reduce the rain impacts on the NRCS and obtain sufficient data pairs for our analysis at extremely high winds, we selected pairs with rain rates below $5 \mathrm{~mm} / \mathrm{h}$. These pairs are gridded by discretizing the wind speeds and incidence angles into $1 \mathrm{~m} / \mathrm{s}$ bins and $1^{\circ}$ bins, respectively. In the two-dimensional bins, data pairs whose NRCS deviates by more than one standard deviation (STD) from the NRCS average are discarded. This simple quality control criterion yields a new NRCS. Figures 2 and 3 show the STD distributions of the old and new NRCSs, respectively. Panels a and $\mathrm{b}$ of each figure display the binned STDs in the wind speed ranges $6-20 \mathrm{~m} / \mathrm{s}$ and $40-70 \mathrm{~m} / \mathrm{s}$, respectively.

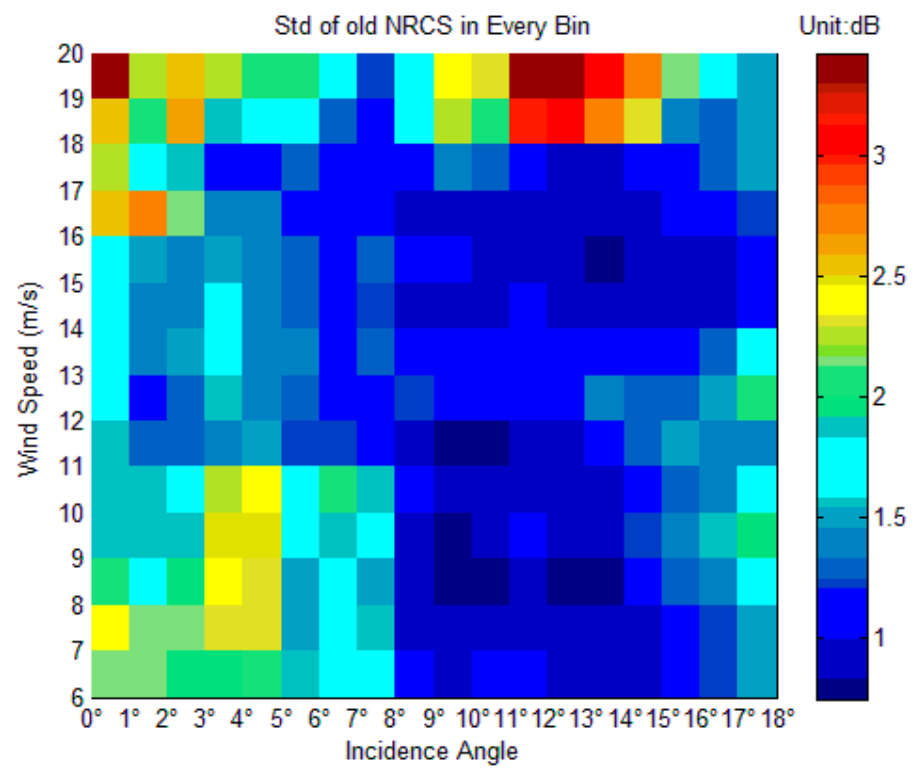

(a)

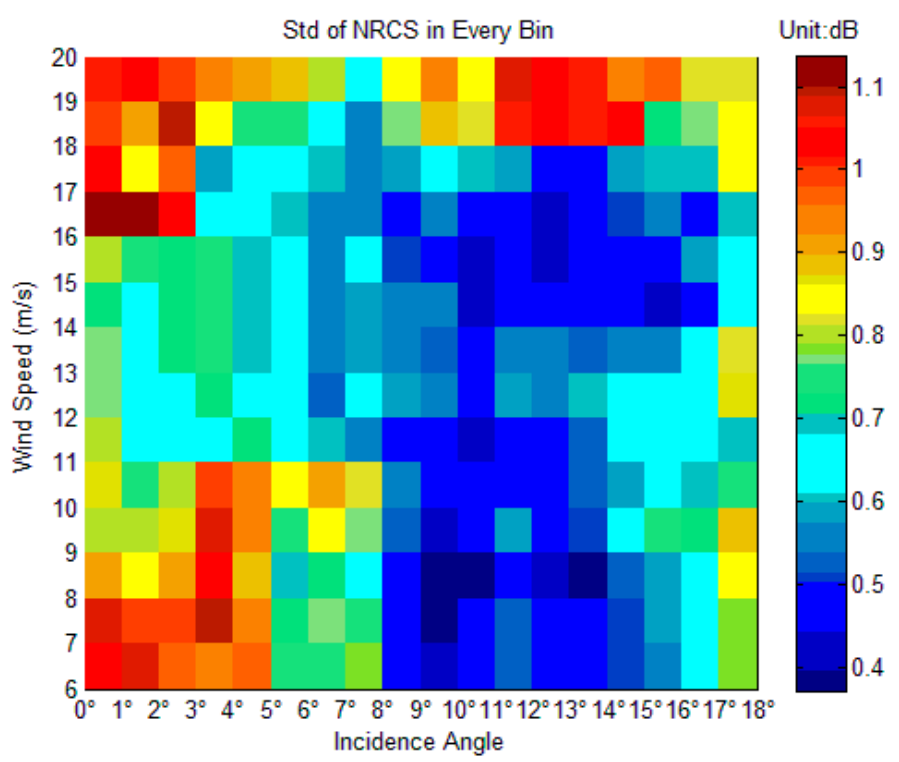

(b)

Figure 2. (a) Distribution of NRCS standard deviations (STDs) in each bin before quality control at wind speed 6-20 m/s. The wind speed is from SFMR and NRCS is from PR. Each collocated data pair contains $1 \mathrm{~s}$ of SFMR data and one NRCS and incidence angle of PR. (b) Distribution of NRCS STDs in each bin after quality control at wind speed $6-20 \mathrm{~m} / \mathrm{s}$. The wind speed is from SFMR and NRCS is from PR. Each collocated data pair contains $1 \mathrm{~s}$ of SFMR data and one NRCS and incidence angle of PR. 


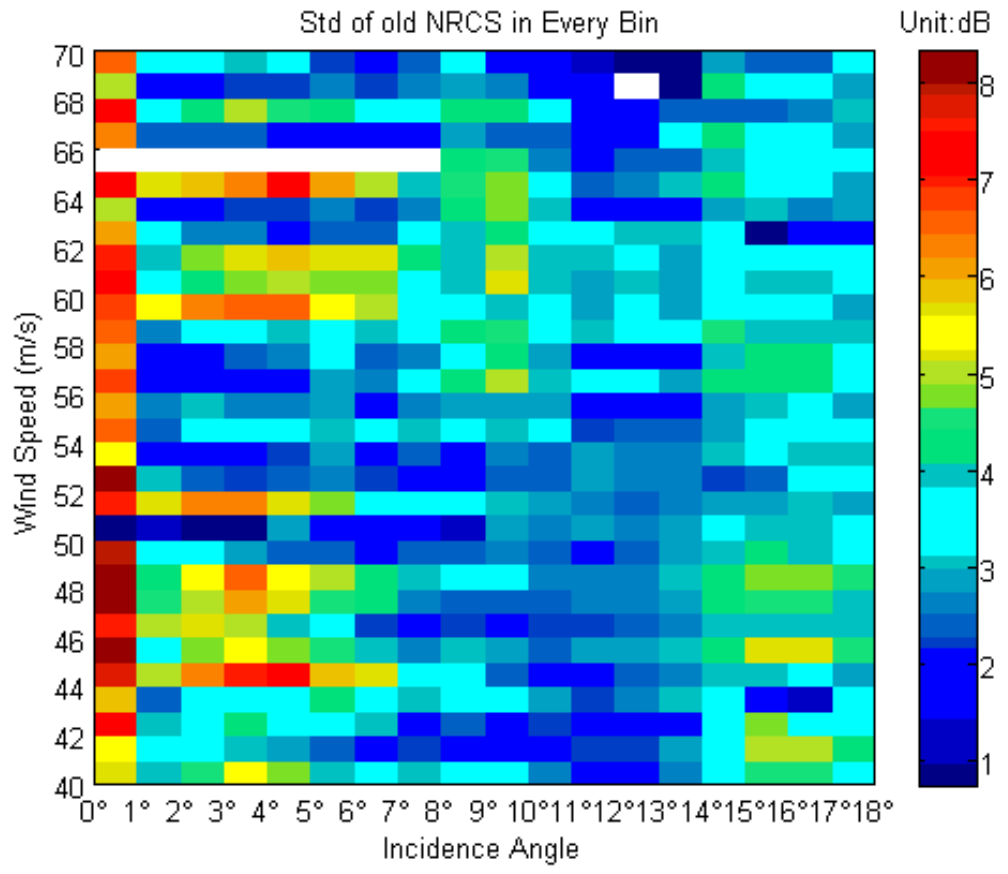

(a)

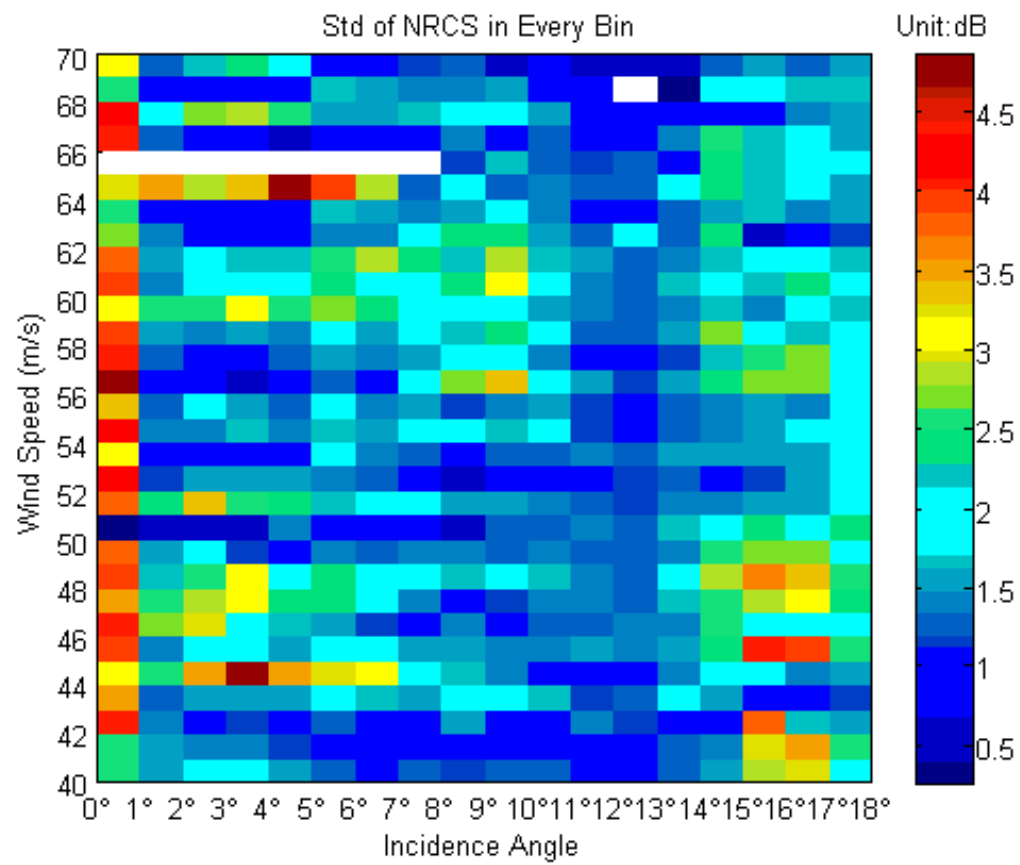

(b)

Figure 3. (a) Distribution of NRCS STDs in each bin before quality control at wind speed 40-70 m/s. The wind speed is from SFMR and NRCS is from PR. Each collocated data pair contains $1 \mathrm{~s}$ of SFMR data and one NRCS and incidence angle of PR. (b) Distribution of NRCS STD in each bin after quality control at wind speed $40-70 \mathrm{~m} / \mathrm{s}$. The wind speed is from SFMR and NRCS is from PR. Each collocated data pair contains $1 \mathrm{~s}$ of SFMR data and one NRCS and incidence angle of PR.

As confirmed in Figures 2 and 3, the simple quality control criterion drastically decreases the STDs. As wind speeds are between 6 and $20 \mathrm{~m} / \mathrm{s}$ (Figure 2), the new STDs are constrained to be within $1.1 \mathrm{~dB}$, whereas the non-controlled STDs are approximately within $3.5 \mathrm{~dB}$. For high wind speeds ranging from 
40 to $70 \mathrm{~m} / \mathrm{s}$ (Figure 3), the NRCS is rendered noisier by the high wind and reduced number of points. In this case, the simple control criterion reduces the largest STDs from approximately $8 \mathrm{~dB}$ to $4.7 \mathrm{~dB}$. Although $4.7 \mathrm{~dB}$ is still below the required accuracy, most of the STDs are within $1.5 \mathrm{~dB}$ (the largest errors occur at $0^{\circ}$ ). The data is acceptable for our analysis, as the PR is accurate to $1 \mathrm{~dB}$.

\section{Results}

To show the results of NRCS from PR clearly, four figures are presented. Figures 4 and 6 study the dependence of NRCS on incidence angle at different wind speeds. Figures 5 and 7 study the dependence of NRCS on wind speed at different incidence angles. In this condition, Figures 4 and 5 illustrate dependence of NRCS on moderate wind condition while Figures 6 and 7 correspond to high wind condition.

\subsection{PR NRCS at Small and Moderate Wind Speeds}

At low incidence angles and wind speeds below $20 \mathrm{~m} / \mathrm{s}$, the NRCS is dominated by a quasi-specular reflection mechanism, and can be simulated by simple formulas [30,31]. Here we validate the NRCSs measured by the TRMM PR by using a geometrical optics model based on non-Gaussian probability density distribution [25]. This model was derived by the NRCS from PR and the wind speed from NDBC buoys, and is formulated as follows:

$$
\sigma_{s p}^{0}(\theta)=\frac{|R(0)|^{2}}{M S S \cdot \cos ^{4} \theta} \exp \left[-\frac{\tan ^{2} \theta}{s v p}\right]\left[a_{1} \frac{\tan ^{4} \theta}{M S S^{2}}-a_{2} \frac{\tan ^{2} \theta}{M S S}+\frac{a_{2}}{4}+1\right]
$$

In Equation (1), coefficients $a_{1}$ and $a_{2}$ are related to the kurtosis of the sea surface slopes. $|R(0)|^{2}$ is effective nadir reflection coefficient. MSS is the mean square slope of sea surface. The four parameters are the function of wind speed, which are given in Li et al. [25]. The NRCS dependences on low incidence angle and low to moderate wind speed are illustrated in Figures 4 and 5, respectively.

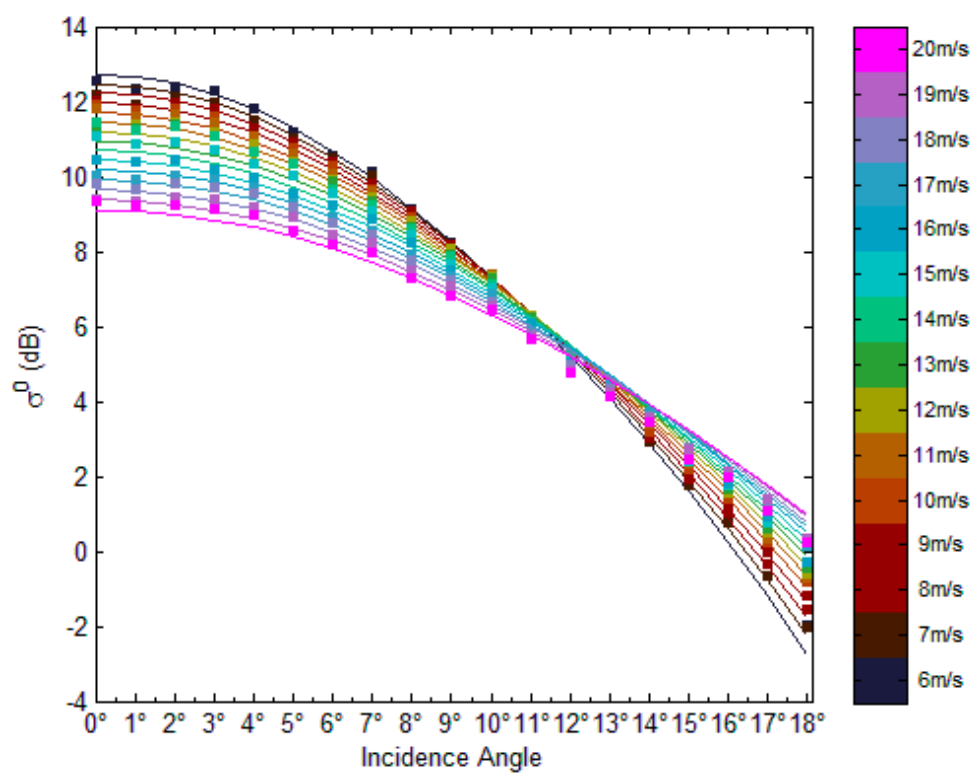

Figure 4. Comparison between collocated NRCS and simulated NRCS, showing NRCS dependence on incidence angle. The squared colored dots are the NRCS collocated from PR and SFMR. The lines are plotted according to the geometrical optics model. The different colors denote different wind speeds.

As shown in Figure 4, the NRCS decreases with increasing incidence angle and is generally consistent with the geometrical optics model predication. Small discrepancies appear at $20 \mathrm{~m} / \mathrm{s}$ wind 
speed and incidence angles of $0^{\circ}$ and $15^{\circ}-18^{\circ}$. The geometrical optics model was derived from a limited number of wind speeds above $15 \mathrm{~m} / \mathrm{s}$, and may not be sufficiently accurate under high wind conditions. Alternatively, the discrepancy could arise from the different wind speed measurement accuracies of SFMR and buoys. Here, the small discrepancies can be neglected. The NRCS becomes independent of wind speed at approximately $12^{\circ}$ incidence angle, slightly larger than reported $10^{\circ}$ in previous studies [32].

Figure 5 shows the dependence of NRCS on wind speed, analyzed with the same dataset as Figure 4. The NRCSs destabilize at near-nadir angles (as evidenced from the STDs in Figure 2b), and the discrepancy increases at $18^{\circ}$. However, the differences between the measured NRCSs and those simulated with the geometrical optics model [25] are less than $1 \mathrm{~dB}$. Therefore, the results are considered to be consistent (given the $1 \mathrm{~dB}$ uncertainty in PR) [24].

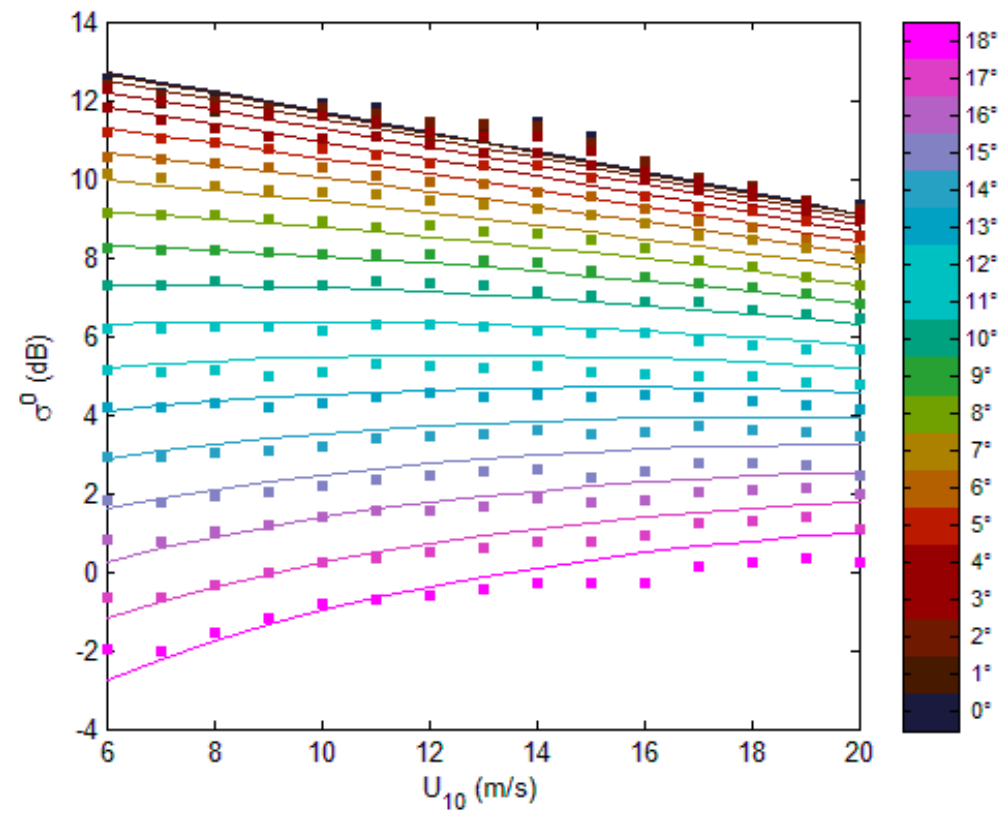

Figure 5. Comparison between collocated NRCS and simulated NRCS, showing NRCS dependence on wind speed. The squared colored dots are the NRCS collocated from PR and SFMR. The lines are plotted according to the geometrical optics model. The different colors denote different wind speeds.

In summary, the NRCS values collocated from PR in the present study display the expected dependences on incidence angle and wind speed in moderate wind conditions.

\subsection{Analysis at Extremely High Wind Speeds}

However, at extremely high wind speeds, the NRCS characteristics deviate from those in moderate wind conditions. To distinguish the NRCS characteristics between the two different wind conditions, we plot the NRCS dependencies on wind speeds and incidence angles, which are shown in Figures 6 and 7 , respectively. The results are derived over the full wind condition that is, sea-surface wind speeds ranging from 6 to $70 \mathrm{~m} / \mathrm{s}$.

Since the rain rates in the data in Figures 6 and 7 are low $(0-5 \mathrm{~mm} / \mathrm{h})$, the rainfall impacts on the NRCS can be ignored. The same figures were also plotted at very low rain rates of $0-2 \mathrm{~mm} / \mathrm{h}$ (results were not shown). The NRCS trends were identical at the low rain rate, except the number of collocated pairs is reduced. Although the plots in Figure 6 appear chaotic, the colors clearly reveal that the wind speeds decrease with increasing incidence angles more dramatically for winds at $40-70 \mathrm{~m} / \mathrm{s}$ than at 6-20 m/s. Figure 7 clarifies that at wind speeds exceeding $40 \mathrm{~m} / \mathrm{s}$, the NRCS characteristics distinctly differ from those of moderate wind conditions. In the $40-70 \mathrm{~m} / \mathrm{s}$ range, the NRCS is disturbed and 
exhibits no clear dependence on wind speed. In extreme high wind conditions, the NRCS is generally very sensitive to low incidence angles and not sensitive to extreme wind speeds.

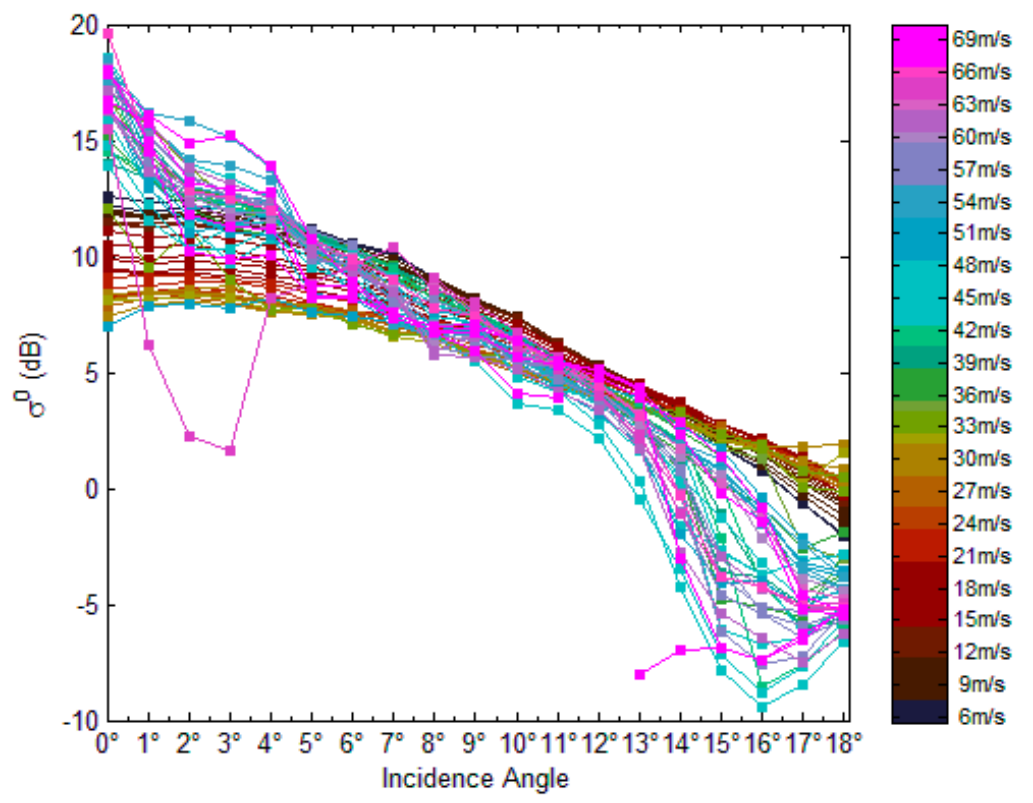

Figure 6. NRCS dependence on incidence angle at different wind speeds. The squared colored dots are the NRCS values collocated from PR and SFMR. The different colors denote different wind speeds.

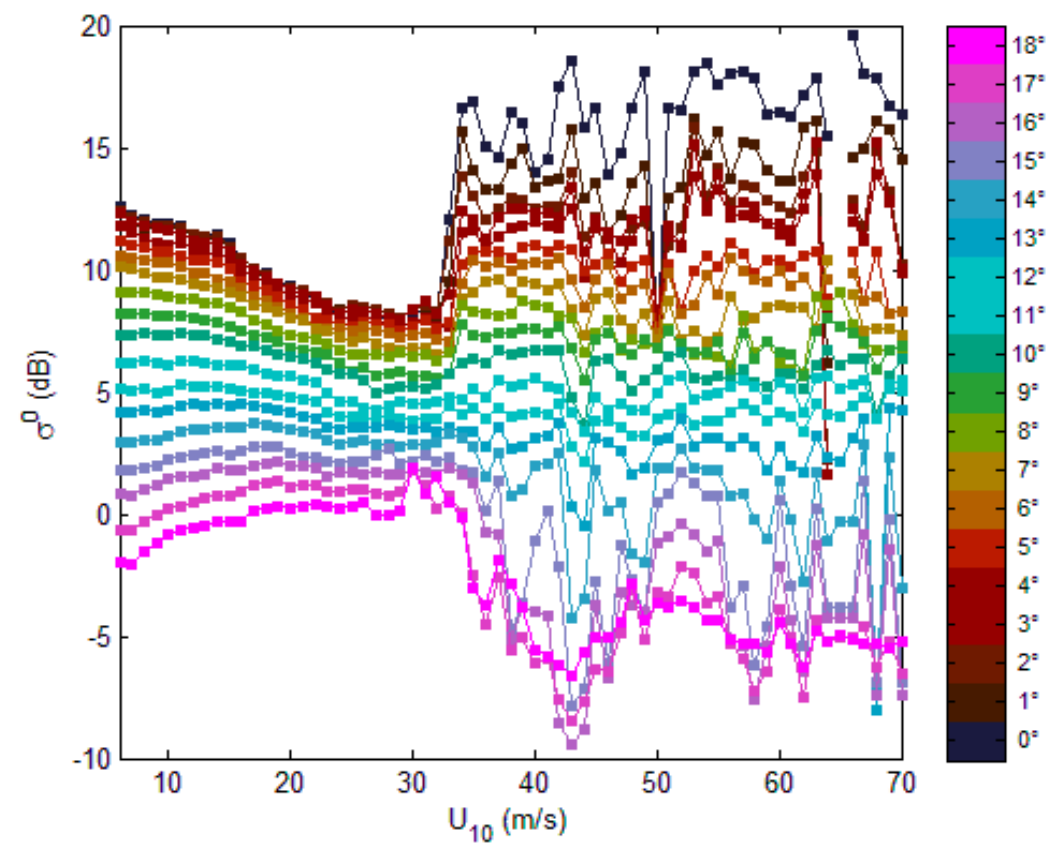

Figure 7. NRCS dependence on wind speed at different incidence angles. The squared colored dots are the NRCS values collocated from PR and SFMR. The different colors denote different incidence angles.

\subsection{Results of Altimeter NRCS}

To determine whether the altimeter NRCS data yield similar results or not, we plot the dependence of NRCS acquired by Jason- 1 and 2 on wind speed. The results are shown in Figure 8. Here, the wind speeds are also collocated from SFMR. The model of Quilfen [22] is also illustrated for comparison. The model coefficients were derived by orthogonal regression between the QuikSCAT and Jason-2 
data at wind speeds between 18 and $30 \mathrm{~m} / \mathrm{s}$. The formula of the model mentioned above is given as follows:

$$
U_{10}=96.68-7.32 \cdot\left(\sigma^{0}+\text { offset }\right) \text { for } \sigma^{0}<10.7896
$$

In Figures 8 and 9, the temporal and spatial intervals decrease from $60 \mathrm{~min}$ to $30 \mathrm{~min}$ and from $100 \mathrm{~km}$ to $50 \mathrm{~km}$ respectively. As the wind speed increases, the number of collocated pairs also decreases. Moreover, both plots present the same tendency of NRCS dependence on wind speed. In general, our results are consistent with Quilfen (green line in the two figures) [22] in the wind speed range from 18 to $30 \mathrm{~m} / \mathrm{s}$. It is important to note that the NRCS becomes large at extremely high wind speeds, similarly to the NRCS values from PR, although the points are few and scattered at wind speeds above $40 \mathrm{~m} / \mathrm{s}$.

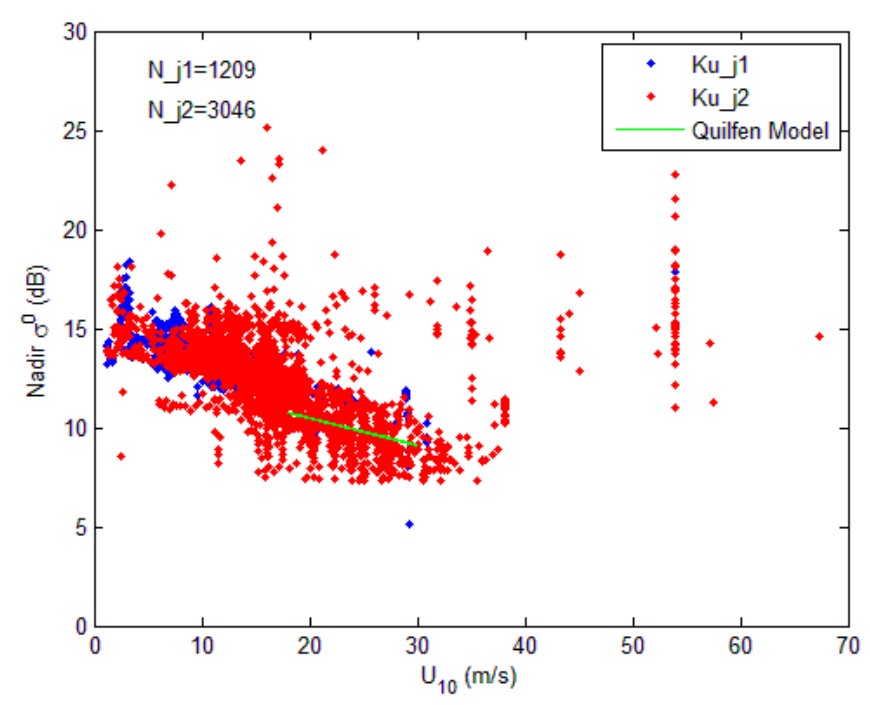

Figure 8. NRCS dependence on wind speed. Blue dots are from Jason-1 Ku-band NRCS while the red ones are Jason-2. The green line is plotted according to Quilfen Model (2011). Here the temporal and spatial distances are $60 \mathrm{~min}$ and $100 \mathrm{~km}$, respectively. $\mathrm{N}_{-} \mathrm{j} 1$ and $\mathrm{N}_{-} \mathrm{j} 2$ show that the number of collocation points are 1209 and 3046, respectively.

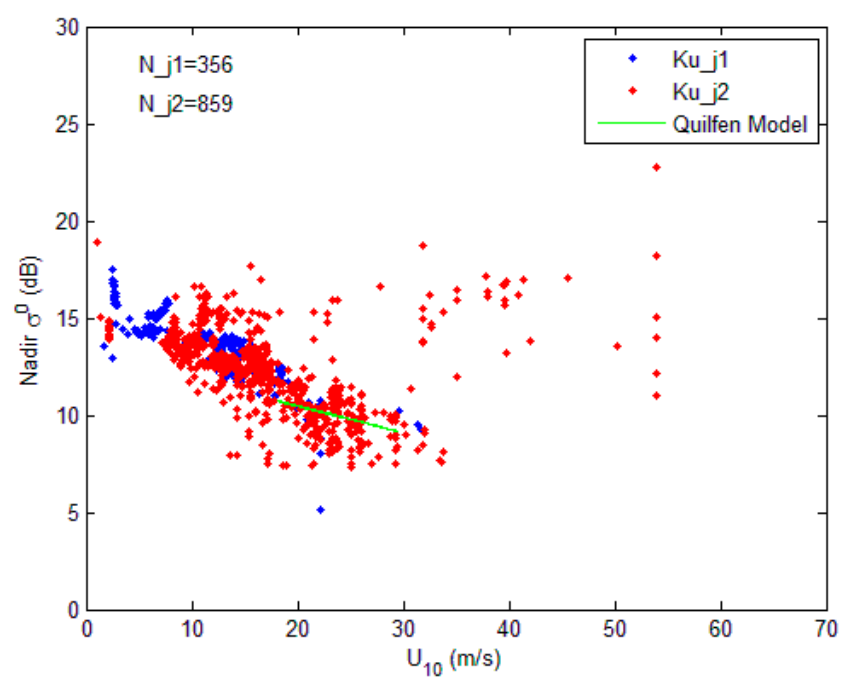

Figure 9. NRCS dependence on wind speed. Blue dots are from Jason-1 Ku-band NRCS while the red ones are Jason-2. The green line is plotted according to Quilfen Model (2011). Here the temporal and spatial distances are $30 \mathrm{~min}$ and $50 \mathrm{~km}$, respectively. N_j1 and N_j2 show that the number of collocation points are 356 and 859 , respectively. 


\section{Discussion}

This study newly presents the NRCS characteristics at extremely high wind speeds. To further describe the phenomenon in detail, we assume that NRCS are constant in the wind speed range from 46 to $70 \mathrm{~m} / \mathrm{s}$ for a given incidence angle. Because NRCS is not sensitive to extreme high winds, we average the NRCSs at different incidence angles and plot them versus incidence angle in Figure 10. Then the result is fitted to the following linear equation:

$$
\sigma_{d B}^{0}(0)=10 \cdot \log _{10}\left(\sigma^{0}\right)=a \cdot \theta+b
$$
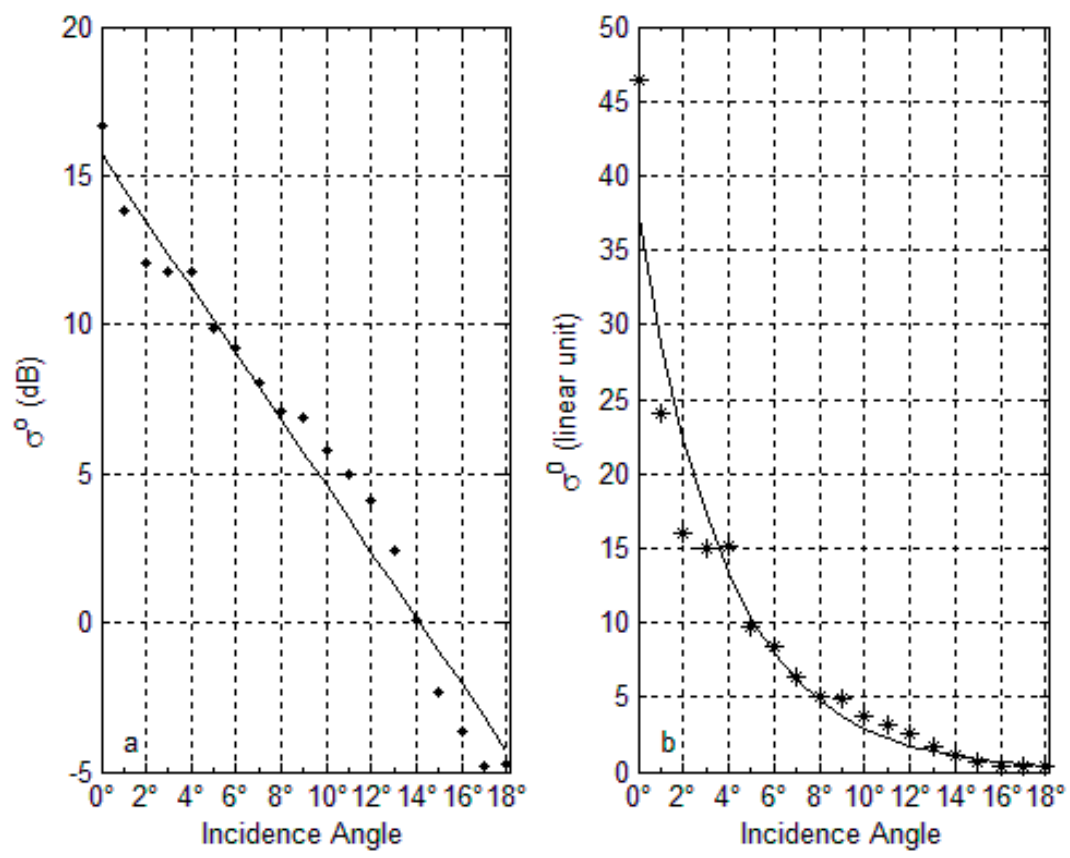

Figure 10. NRCS dependence on incidence angle under extreme wind conditions. (Left) in units of dB; (Right) in linear units.

The linear fitting yields $a=-1.1097$ and $b=15.6995$. The NRCS and $\theta$ are expressed in $\mathrm{dB}$ and degrees, respectively. Near the nadir angle, the NRCS is very large and decreases drastically with small increments in incidence angle. Generally, the decrease in NRCS with increasing incidence angle obeys the simple Equation (3). This newly found phenomenon may be useful in the following research directions.

\subsection{Validation of $C_{d}$}

From the late 1960s through the 1990s, the drag coefficient $C_{d}$ was considered to be positively correlated with the sea surface wind speed. However, this universally accepted relationship is only confirmed for wind speeds under $26 \mathrm{~m} / \mathrm{s}$, because no high wind speed observations can be acquired especially in regions over the deep ocean [33].

In 2003, Powell et al. showed that $C_{d}$ decreases at $U_{10}>33 \mathrm{~m} / \mathrm{s}$. The team hypothetically attributed this reduction to sea foam, spray and bubbles resulting from breakage of steep wave faces, which forms a slip surface [34]. Donelan and his team [35] observed that the drag coefficient is saturated as sea surface wind speeds are above $33 \mathrm{~m} / \mathrm{s}$. They concluded that as the wind speed over the open ocean increases from gale to hurricane force values, continuous intense wave-breaking occurs and the crests are essentially blown away by the strong winds. This mechanism fills the air with sea spray and the surface with spume, altering its frictional and roughness characteristics [35]. 
Many subsequent papers have studied the nonlinearity and parametrization of $C_{d}$ in these conditions (e.g., [36-38]).

For moderate wind speeds as shown in Figure 4, the dependence of NRCS on incidence angle complies with quasi-specular backscattering theory. As shown in Figure 7, the decrease of NRCS with increasing incidence angles in the wind speed range from 40 to $70 \mathrm{~m} / \mathrm{s}$ is more dramatic than in that from 6 to $20 \mathrm{~m} / \mathrm{s}$. The distinction indicates that the sea surface at extreme wind speed is relatively "smooth" to Ku-band electromagnetic microwaves, in contrast to at low and moderate wind speeds. That is, the NRCS is very sensitive to low incidence angles under extreme wind conditions and insensitive to the extreme wind speed. Due to this relative "smooth" sea surface, the $C_{d}$ under high wind conditions should be smaller than that of in moderate wind circumstances. Therefore, the phenomenon revealed in this paper validates the $C_{d}$ decreases at extremely high wind conditions, in contrast to moderate wind conditions. Hwang $[39,40]$ derived an experimental formula for $C_{d}$ based on previous studies, but this formula is limited to wind speeds below $50 \mathrm{~m} / \mathrm{s}$. According to Figure 7 , the sea surface remains "smooth" at wind speeds up to $70 \mathrm{~m} / \mathrm{s}$.

In previous studies, the $C_{d}$ levels off at $32-33 \mathrm{~m} / \mathrm{s}$; in others, saturation occurs at $22-23 \mathrm{~m} / \mathrm{s}$ [33]. Figure 7 is consistent with $C_{d}$ saturation at $32-33 \mathrm{~m} / \mathrm{s}$; otherwise, the NRCS should begin dramatically varying at $22-23 \mathrm{~m} / \mathrm{s}$. Besides validating the remote sensing data, the new characteristics may potentially assist anticipated satellites missions in the future.

\subsection{CFOSAT}

The CFOSAT satellite is scheduled for launch in 2018. The payload instruments are Surface Waves Investigation and Monitoring (SWIM) and a rotating scatterometer. SWIM operates in the $\mathrm{Ku}$-band, with VV polarization, at small incidence angles. At low wind speeds, the interface between the atmosphere and sea surface is well-clarified. Moreover, the VV-polarized NRCS is similar to the $\mathrm{HH}$-polarized NRCS at small incidence angles for the quasi-specular scattering mechanism. Therefore, at high wind conditions, the NRCS acquired from VV polarization probably shares similar dependence on incidence angle to those acquired from $\mathrm{HH}$.

In extreme wind conditions, the atmosphere ocean interface essentially disappears and the sea surface becomes relatively "smooth" for the Ku-band (or the NRCS will conform to the quasi-specular backscattering results, such as Equation (1)). Beneath the interface are the water balls surrounded by the atmosphere and beneath the water balls may be the ocean water fluctuation. CFOSAT SWIM detects the ocean wave spectra based on the tilted ocean surface modulation, that is, the variations of backscattering cross section of long waves are linearly proportional to the sea surface slopes:

$$
\partial \sigma / \sigma=\alpha \cdot \partial \xi / \partial x
$$

Here, $\sigma$ is backscattering cross section of long waves, $\alpha$ the modulation transfer function (related to the incidence angle), and $\partial \xi / \partial x$ the sea surface slope. After spectral estimation, the sea wave spectra can be acquired [41]. However, in extreme wind conditions the information of ocean water fluctuation at the bottom cannot be acquired by the Ku-band EM waves because the relatively "smooth" surface backscatters EM energy and thus no fluctuation signals can be used to retrieve the ocean water fluctuation. The dramatic decrement of NRCS with increasing incidence angle can flag the presence of a high sea state; that is, can qualitatively indicate the severity of the sea-wave spectra.

\subsection{Altimeter}

In the near future, wide swath ocean altimeters (WSOA), HY-2B etc. will be launched. They all operate at small incidence angles. Here, a preliminary NRCS dependence on high wind speed is shown, and more validation is needed at nadir incidence angles.

The potential impacts of the NRCS characteristics at extremely high wind speeds on altimetry may be the distorted waveforms reflected from the "smooth" sea surface. The waveforms will peak 
with very steep leading and sharp trailing edges, just like a delta function, which appears when the nadir direction surface is land occupied by ice. This phenomenon will lead to errors for estimates of the sea surface height or the wrong land flag. Thus, this influence cannot be neglected.

\section{Conclusions}

In this paper, in order to analyze the NRCS at low incidence angles at extreme wind condition, the wind speed from SFMR and NRCS from PR on TRMM or altimeters are collocated. After the data statistics are computed and a simple quality control criterion is specified, the NRCS dependencies on incidence angle from $0^{\circ}$ to $18^{\circ}$ and wind speed from $6 \mathrm{~m} / \mathrm{s}$ to $70 \mathrm{~m} / \mathrm{s}$ are shown.

The NRCS values at moderate and low wind speeds are compared with those from a geometrical optical model, which confirms the consistency among them. Figures 4 and 5 show that there are only small differences at wind speed $20 \mathrm{~m} / \mathrm{s}$ and incidence angles $0^{\circ}, 15^{\circ}-18^{\circ}$. The optical model is developed by the NRCS from PR and wind speeds from NDBC. Taking into account the SFMR wind speed error in contrast to that from NDBC, the NRCS dependence is generally consistent with that of the optical model.

At extremely high wind speeds, the characteristics of the NRCS are shown in Figures 6 and 7. These results have not been reported previously in the literature. We have found that the NRCS increases drastically with increasing wind speeds from about $32 \mathrm{~m} / \mathrm{s}$ to $40 \mathrm{~m} / \mathrm{s}$ at near-nadir incidence angles and then becomes generally invariable, for higher winds. At about $11^{\circ}-13^{\circ}$, the NRCS is nearly invariant for all kinds of wind conditions (wind speeds from $6 \mathrm{~m} / \mathrm{s}$ to $70 \mathrm{~m} / \mathrm{s}$ ). When the incidence angles increase to about $18^{\circ}$, the saturation is shown to occur at around $30 \mathrm{~m} / \mathrm{s}-32 \mathrm{~m} / \mathrm{s}$, as expected, which is the same as that of scatterometers. However, the NRCS at near $18^{\circ}$ decreases drastically from $32 \mathrm{~m} / \mathrm{s}$ to $40 \mathrm{~m} / \mathrm{s}$ and then becomes nearly constant for higher winds. Generally, the NRCS values at extremely high wind speeds have large values at near-nadir incidence angels and then decrease drastically with increasing incidence angles. In Figures 8 and 9, the matchups from Jason- 1 and 2 and SFMR are collected; the same NRCS characteristics at nadir incidence angles as found for PR can also confirm the results, although the number of points at extremely high wind speeds is too small to be statistically significant.

The NRCS dependence on incidence angles at extremely high wind speed is generally presented in Figure 10 and a simple formula is given by Equation (3). In physical terms, at extremely high wind speeds for Ku-band EM wave and HH polarization, the sea surface becomes very "smooth", just like a "mirror", and only this assumption can explain the characteristics of the NRCS values in Figure 10. This is consistent with the $C_{d}$ decrement at high wind speed, which has been discovered by many researchers with in-situ measurements.

The new discovery may have potential use for the future missions, such as CFOSAT, WSOA, etc. Because of the scarcity of the data at high wind speeds, the data points are not enough for validation at $0^{\circ}$ incidence angle and the phenomenon can be verified in more detail by NRCS at nadir angles and medium angles.

Acknowledgments: This work was supported in part by the National Key Research and Development Program of China under Grant 2016YFC1401005 and 2016YFC1401001, in part by the National Science Foundation of China for Outstanding Young Scientist under Grant 41622604, in part by the National Science Foundation of China under Grant 41476158, in part by the Excellent Youth Science Foundation of Jiangsu Province under Grant BK20160090, in part by the Startup for Introducing Talent of NUIST, and the CFOSAT project. We would also like to acknowledge the Goddard Earth Sciences (GES) Data and Information Services Center (DISC) for the straightforward and rapid electronic access to the TRMM PR data, Jason-1 and 2 data from AVISO website and HRD, NOAA for the SFMR data. Canadian Space Agency program DUAP contributed to the support of W. Perrie.

Author Contributions: Xiuzhong Li carried out the research and prepared the manuscript under the guidance of Biao Zhang and Alexis Mouche. Yijun He and Will Perrie contributed to the preparation of the paper through editing.

Conflicts of Interest: The authors declare no conflict of interest. 


\section{References}

1. Dai, H.; Du, L.; Wang, Y.; Wang, Z. A Modified CFAR Algorithm Based on Object Proposals for Ship Target Detection in SAR Images. IEEE Geosci. Remote Sens. Lett. 2016, 13, 1925-1929. [CrossRef]

2. Martin, A.C.; Gommenginger, C.; Marquez, J.; Doody, S.; Navarro, V.; Buck, C. Wind-Wave induced velocity in ATI SAR Ocean Surface Currents: First experimental evidence from an airborne campaign. J. Geophys. Res. Oceans 2016, 121, 1640-1653. [CrossRef]

3. Caudal, G.; Hauser, D.; Valentin, R.; Gac, C.L. KuROS: A New Airborne Ku-Band Doppler Radar for Observation of Surfaces. J. Atmos. Ocean. Technol. 2014, 31, 2223-2245. [CrossRef]

4. Stoffelen, A.; Anderson, D. Scatterometer data interpretation: Estimation and validation of the transfer function CMOD4. J. Geophys. Res. Oceans 1997, 102, 7767-7786. [CrossRef]

5. Quilfen, Y.; Chapron, B.; Elfouhaily, T.; Katsaros, K.; Tournadre, J. Observation of tropical cyclones by high-resolution scatterometry. J. Geophys. Res. Oceans 1998, 103, 7767-7786. [CrossRef]

6. Jones, W.L.; Cardone, V.; Pierson, W.; Zec, J.; Rice, L.; Cox, A.; Sylvester, W. NSCAT high-resolution surface wind measurements in Typhoon Violet. J. Geophys. Res. Oceans 1999, 104, 11247-11260. [CrossRef]

7. Donnelly, W.J.; Carswell, J.R.; McIntosh, R.E.; Chang, P.S.; Wilkerson, J.; Marks, F.; Black, P.G. Revised ocean backscatter models at $\mathrm{C}$ and $\mathrm{Ku}$ band under high-wind conditions. J. Geophys. Res. Oceans 1999, 104, 11485-11497. [CrossRef]

8. Carswell, J.R.; Knapp, E.J.; Chang, P.S.; Black, P.D.; Marks, F.D. Limitations of scatterometry high wind speed retrieval. In Proceedings of the IEEE 2000 International Geoscience and Remote Sensing Symposium (IGARSS), Honolulu, HI, USA, 24-28 July 2000.

9. Fernandez, D.E.; Carswell, J.R.; Frasier, S.; Chang, P.S.; Black, P.G.; Marks, F.D. Dual-polarized C- and $\mathrm{Ku}$-band ocean backscatter response to hurricane-force winds. J. Geophys. Res. Oceans 2006. [CrossRef]

10. Zhang, B.; Perrie, W. Cross-polarized synthetic aperture radar: A new potential measurement technique for hurricanes. Bull. Am. Meteorol. Soc. 2012, 93, 531-541. [CrossRef]

11. Zhang, B.; Perrie, W.; Zhang, J.A.; Uhlhorn, E.W.; He, Y. High-resolution hurricane vector winds from C-band dual-polarization SAR observations. J. Atmos. Ocean. Technol. 2014, 31, 272-286. [CrossRef]

12. Horstmann, J.; Wackerman, C.; Falchetti, S.; Maresca, S. Tropical cyclone winds retrieved from synthetic aperture radar. Oceanography 2013, 26, 46-57. [CrossRef]

13. Fois, F.; Hoogeboom, P.; Le Chevalier, F.; Stoffelen, A. Future Ocean Scatterometry: On the Use of Cross-Polar Scattering to Observe Very High Winds. IEEE Trans. Geosci. Remote Sens. 2015, 53, 5009-5020. [CrossRef]

14. Sapp, J.; Chang, P.; Jelenak, Z.; Frasier, S.; Hartley, T. Cross-polarized C-band sea-surface NRCS observations in extreme winds. In Proceedings of the 2016 IEEE International Geoscience and Remote Sensing Symposium (IGARSS), Beijing, China, 10-15 July 2016.

15. Freilich, M.H.; Vanhoff, B.A. The Relationship between Winds, Surface Roughness, Radar Backscatter at Low Incidence Angles from TRMM Precipitation Radar Measurements. J. Atmos. Ocean. Technol. 2003, 20, 549-562. [CrossRef]

16. Chu, X.; He, Y.; Karaev, V.Y. Relationships Between Ku-Band Radar Backscatter and Integrated Wind and Wave Parameters at Low Incidence Angles. IEEE Trans. Geosci. Remote Sens. 2012, 50, 4599-4609. [CrossRef]

17. Chu, X.; He, Y.; Chen, G. Asymmetry and anisotropy of microwave backscatter at low incidence angles. IEEE Trans. Geosci. Remote Sens. 2012, 50, 4014-4024. [CrossRef]

18. Boisot, O.; Nouguier, F.; Chapron, B.; Guérin, C.A. The GO4 model in near-nadir microwave scattering from the sea surface. IEEE Trans. Geosci. Remote Sens. 2015, 53, 5889-5900. [CrossRef]

19. Young, I.R. An estimate of the Geosat altimeter wind speed algorithm at high wind speeds. J. Geophys. Res. Oceans 1993, 98, 20275-20285. [CrossRef]

20. Quilfen, Y.; Chapron, B.; Tournadre, J. Altimeter dualfrequency observations of surface winds, waves, and rain rate in tropical cyclone Isabel. J. Geophys. Res. Oceans 2006, 111, C01004. [CrossRef]

21. Quilfen, Y.; Chapron, B.; Tournadre, J. Satellite Microwave Surface Observations in Tropical Cyclones. Mon. Weather Rev. 2010, 138, 421-437. [CrossRef]

22. Quilfen, Y.; Vandemark, D.; Chapron, B.; Feng, H.; Sienkiewicz, J. Estimating Gale to Hurricane Force Winds Using the Satellite Altimeter. J. Atmos. Ocean. Technol. 2011, 28, 453-458. [CrossRef]

23. Quartly, G.; Guymer, T.; Srokosz, M. Back to basics: Measuring rainfall at sea: Part 2-Space-borne sensors. Weather 2002, 57, 363-366. [CrossRef] 
24. Liao, L.; Meneghini, R. Changes in the TRMM Version-5 and Version-6 Precipitation Radar Products Due to Orbit Boost. J. Meteorol. Soc. Jpn. 2009, 87, 93-107. [CrossRef]

25. Li, X.; He, Y.; Zhang, B.; Ge, J.; Chu, X. A geometrical optics model based on the non-Gaussian probability density distribution of sea surface slopes for wind speed retrieval at low incidence angles. Int. J. Remote Sens. 2016, 37, 537-550. [CrossRef]

26. Uhlhorn, E.W.; Black, P.G. Verification of remotely sensed sea surface winds in hurricanes. J. Atmos. Ocean. Technol. 2003, 20,99-116. [CrossRef]

27. Knapp, E.; Carswell, J.; Swift, C. A dual polarization multi-frequency microwave radiometer. Paper Presented at the 2000 IEEE International Geoscience and Remote Sensing Symposium, New York, NY, USA, 24-28 July 2000.

28. Uhlhorn, E.W.; Black, P.G.; Franklin, J.L.; Goodberlet, M.; Carswell, J.; Goldstein, A.S. Hurricane surface wind measurements from an operational stepped frequency microwave radiometer. Mon. Weather Rev. 2007, 135, 3070-3085. [CrossRef]

29. Bradley, W.K.; Uhlhorn, E.W. Improved stepped frequency microwave radiometer tropical cyclone surface winds in heavy precipitation. J. Atmos. Ocean. Technol. 2014, 31, 2392-2408.

30. Barrick, D.E. Rough surface scattering based on specular point theory. IEEE Trans. Antennas Propag. 1968, 16, 449-454. [CrossRef]

31. Bringer, A.; Guerin, C.; Chapron, B.; Mouche, A.A. Peakedness effects in near-nadir radar observations of the sea surface. IEEE Trans. Geosci. Remote Sens. 2012, 50, 3293-3301. [CrossRef]

32. Hesany, V.; Plant, W.J.; Keller, W.C. The normalized radar cross section of the sea at 10 incidence. IEEE Trans. Geosci. Remote Sens. 2000, 38, 64-72. [CrossRef]

33. Bryant, K.M.; Akbar, M. An Exploration of Wind Stress Calculation Techniques in Hurricane Storm Surge Modeling. J. Mar. Sci. Eng. 2016, 4, 58. [CrossRef]

34. Powell, M.D.; Vickery, P.J.; Reinhold, T.A. Reduced drag coefficient for high wind speeds in tropical cyclones. Nature 2003, 422, 279-283. [CrossRef] [PubMed]

35. Donelan, M.A.; Haus, B.K.; Reul, N.; Plant, W.J.; Stiassnie, M.; Graber, H.C.; Brown, O.B.; Saltzman, E.S. On the limiting aerodynamic roughness of the ocean in very strong winds. Geophys. Res. Lett. 2004. [CrossRef]

36. Moon, I.J.; Ginis, I.; Hara, T.; Thomas, B. A physics-based parameterization of air-sea momentum flux at high wind speeds and its impact on hurricane intensity predictions. Mon. Weather Rev. 2007, 135, 2869-2878. [CrossRef]

37. Zhao, W.; Liu, Z.; Dai, C.; Song, G.; Lv, Q. Typhoon air-sea drag coefficient in coastal regions. J. Geophys. Res. Oceans 2015, 120, 716-727. [CrossRef]

38. Bi, X.; Gao, Z.; Liu, Y.; Liu, F.; Song, Q.; Huang, J.; Huang, H.; Mao, W.; Liu, C. Observed drag coefficients in high winds in the near offshore of the South China Sea. J. Geophys. Res. Atmos. 2015, 120, 6444-6459. [CrossRef]

39. Hwang, P.A. A note on the ocean surface roughness spectrum. J. Atmos. Ocean. Technol. 2011, 28, 436-443. [CrossRef]

40. Hwang, P.A. Foam and roughness effects on passive microwave remote sensing of the ocean. IEEE Trans. Geosci. Remote Sens. 2012, 50, 2978-2985. [CrossRef]

41. Hauser, D.; Soussi, E.; Thouvenot, E.; Rey, L. SWIMSAT: A real-aperture radar to measure directional spectra of ocean waves from space-Main characteristics and performance simulation. J. Atmos. Ocean. Technol. 2001, 18, 421-437. [CrossRef]

(C) 2017 by the authors. Licensee MDPI, Basel, Switzerland. This article is an open access article distributed under the terms and conditions of the Creative Commons Attribution (CC BY) license (http:/ / creativecommons.org/licenses/by/4.0/). 